\title{
Transient Efficacy of Tofacitinib in Alopecia Areata Universalis
}

\author{
Florian Anzengruber ${ }^{\mathrm{a}} \quad$ Julia-Tatjana Maul ${ }^{\mathrm{a}} \quad$ Jivko Kamarachev ${ }^{\mathrm{a}}$ \\ Ralph M. Trüeb ${ }^{b}$ Lars E. French ${ }^{a} \quad$ Alexander A. Navarini ${ }^{a}$ \\ ${ }^{a}$ Department of Dermatology, University Hospital of Zurich, Zurich, and ${ }^{b}$ Dermatologische \\ Praxis und Haarcenter, Wallisellen, Switzerland
}

\section{Key Words}

Alopecia areata universalis · Tofacitinib · Janus kinase inhibitors

\begin{abstract}
Alopecia areata is a common autoimmune disorder that targets hair follicles. Swarms of lymphocytes surround the basis of the follicles, inducing loss of pigmented terminal hair and subsequently inhibit further hair growth. Depending on the extent of involvement, alopecia areata can be associated with a dramatic reduction of quality of life. Currently, no targeted treatment option is available, and topical immune therapies or immunosuppressive drugs are typically used with mixed success. Recently, several cases of alopecia areata responding to Janus kinase inhibitors were published. Here, we report on a businessman with alopecia areata universalis who was treated with tofacitinib. We observed initial signs of hair regrowth in the same timeframe as previously reported, but efficacy quickly waned again, leading to renewed effluvium. Thus, even though tofacitinib and ruxolitinib are a promising new treatment option, we have yet to learn more about their potential role in each particular patient's individual treatment strategy.

\section{Introduction}

Alopecia areata (AA), a nonscarring type of hair loss, is the most prevalent autoimmune disease, with a lifetime prevalence of $1.7 \%[1,2]$. Men and women are equally affected, and onset of the disease can occur at any age; however, most cases start before the age of 30 [3]. Fifty percent of children and adolescents with AA suffer from depression [4]. Autoimmune diseases such as vitiligo, thyroid disease and atopic diseases have been associated with AA [5]. The genetic architecture has also been described [6]. A high concordance rate among

\section{KARGER}

PD Dr. Alexander A. Navarin

Dermatologische Klinik

Universitätsspital Zürich

Gloriastrasse 31, CH-8091 Zurich (Switzerland)

E-Mail alexander.navarini@usz.ch 
monozygotic twins was reported [7, 8], and a positive family history is linked to AA [9-11]. Additionally, human leukocyte antigen (HLA)-DQB1, HLA-DRB1, HLA-A, HLA-B, HLA-C and also the genes NOTCH4, MICA, PTPN22 and AIRE were found to be associated with AA [2,12]. The first genome-wide association study found 8 loci (table 1) with genome-wide significance containing multiple genes involved in the adaptive T cell-driven immune response [2]. The current view is that both genetic and immune factors contribute to the development of AA (fig. 1). In addition, much less well-defined environmental and psychologic elements are sure to have some influence as well.

A Cochrane review analyzing 17 randomized controlled trials concluded that there is currently no effective evidence-based treatment for AA. Even though topical minoxidil, cyclosporine, corticosteroids (as well as systemic corticosteroids) and photodynamic therapy are used, there is no firm evidence of superiority compared to placebo [13]. However, in daily clinical use, all these drugs are used with apparent success. Recently, Suarez-Farinas et al. [14] performed microarray and RT-PCR of 27 lesional and 17 nonlesional samples of patients with AA. It was shown that TH1, TH2, and IL-23 cytokine were increased, while TH17/TH22 skewing was lacking [14]. Additionally, also ustekinumab, a monoclonal IL$12 / 23$ inhibitor, is of interest as a potential treatment of AA. There have been case reports that ustekinumab causes AA [15-17], but in contrast, successful treatments with significant increase of hair growth were reported $[18,19]$.

The possibility of reversal of AA by Janus kinase (JAK) inhibitors was successfully shown in the murine model [20]. Additionally, Craiglow and King [21] published a case of a 25-yearold patient with psoriasis vulgaris and alopecia universalis, a type of AA in which complete loss of hair of the entire body is observed. After treatment with tofacitinib, a JAK1/3 inhibitor approved for the treatment of rheumatoid arthritis, complete regrowth of hair was observed [21]. Also, one case from Germany responded well to tofacitinib (U. Mrowietz, personal communication). In another case report, 3 patients suffering from AA were successfully treated with ruxolitinib, a JAK1/2 inhibitor approved for myelofibrosis [20].

\section{Case}

A 51-year-old businessman with alopecia universalis presented to our clinic. His past medical history revealed a bilateral chronic retinal vasculitis and uveitis, for which he had been treated in the past with various drugs such as methotrexate, azathioprine, oral prednisolone and infliximab. Two years before, while receiving infliximab and azathioprine, sudden loss of hair had occurred on the temples, and drug-induced AA was suspected. Even though the drug treatment was stopped, the AA worsened. Four months later, the retinal vasculitis showed progression of disease as well, so infliximab and azathioprine were started again. A dermatologic consultation was sought. Subsequently, treatment with topical and oral steroids, followed by topical diphenylcyclopropenone as well as oral methotrexate (up to $30 \mathrm{mg}$ per week) was initiated. However, no regrowth of hair was observed after 6 months.

Upon his first consultation in our clinic, a skin biopsy was performed on the scalp. A biopsy confirmed sparse lymphocytic infiltrates along nonsclerotic fibrous tracts extending along the site of previous follicles. The diagnosis of a nonfibrosing AA was confirmed. Compassionate use of tofacitinib $5 \mathrm{mg}$ twice daily was initiated. Methotrexate was continued at $15 \mathrm{mg}$ per week. The scalp remained unchanged for 2 months (fig. 2a), but after 3 months of treatment, growth of short terminal pigmented hair was detected (fig. 2b). These, however, disappeared again within a single month, resulting in renewed complete alopecia (fig. 2c). 
Anzengruber et al.: Transient Efficacy of Tofacitinib in Alopecia Areata Universalis

\section{Discussion}

The efficacy of tofacitinib has been suggested by murine experiments and by one case presentation [20, 21]. Tofacitinib citrate (Xeljanz ${ }^{\circledR}$ ) abrogates IL-15 signaling [22] and thus mediates IL-15 activation of lymphocytes [14]. Even though the initial clinical results were promising, the efficacy of tofacitinib waned again in our patient. This was even more striking when considering that the patient had additional immunosuppression by methotrexate for his retinal vasculitis. Notably, methotrexate monotherapy has been shown to be a safe treatment option for AA as well [15]. Another potential reason for treatment failure could have been the presence of antibodies specific for hair follicles [23, 24]; however, we were unable to measure and rule them out.

The clinical observation in this patient could be interpreted as follows: suppression of AA by tofacitinib is an active process that, if too weak, may not tip the balance towards stable hair regrowth but instead allow a reversion to a completely alopecic state. Although here we report only on a single case with all its limitations, it will be interesting to analyze the outcome of randomized clinical trials, especially in patients not showing efficacy to tofacitinib. Also, our observation may prompt the question whether combinations of immunosuppressive drugs potentiate or inhibit each other in AA.

\section{Statement of Ethics} lished.

The authors state that the patient gave informed consent to have his photographs pub-

\section{Disclosure Statement}

F.A. is funded by a HSM2 (Hochspezialisierte Medizin) grant awarded by the Kanton of Zurich, Switzerland. A.A.N. is funded by the Promedica and Bruno-Bloch Foundation.

\section{References}

1 Hon KL, Leung AK: Alopecia areata. Recent Pat Inflamm Allergy Drug Discov 2011;5:98-107.

2 Jabbari A, et al: Genetic basis of alopecia areata: a roadmap for translational research. Dermatol Clin 2013;31:109-117.

3 Madani S, Shapiro J: Alopecia areata update. J Am Acad Dermatol 2000;42:549-566; quiz 567-570.

4 Ghanizadeh A, Ayoobzadehshirazi A: A review of psychiatric disorders comorbidities in patients with alopecia areata. Int J Trichology 2014;6:2-4.

-5 Hordinsky MK: Overview of alopecia areata. J Investig Dermatol Symp Proc 2013;16:S13-S15.

-6 Petukhova L, et al: Genome-wide association study in alopecia areata implicates both innate and adaptive immunity. Nature 2010;466:113-117.

7 Jackow C, et al: Alopecia areata and cytomegalovirus infection in twins: genes versus environment? J Am Acad Dermatol 1998;38:418-425.

8 Rodriguez TA, et al: Concordance rate of alopecia areata in identical twins supports both genetic and environmental factors. J Am Acad Dermatol 2010;62:525-527.

-9 Blaumeiser B, et al: Familial aggregation of alopecia areata. J Am Acad Dermatol 2006;54:627-632.

10 McDonagh AJ, Tazi-Ahnini R: Epidemiology and genetics of alopecia areata. Clin Exp Dermatol 2002;27:405409.

11 van der Steen P, et al: The genetic risk for alopecia areata in first degree relatives of severely affected patients. An estimate. Acta Derm Venereol 1992;72:373-375.

$\checkmark 12$ Gilhar A, Paus R, Kalish RS: Lymphocytes, neuropeptides, and genes involved in alopecia areata. J Clin Invest 2007;117:2019-2027. 
Anzengruber et al.: Transient Efficacy of Tofacitinib in Alopecia Areata Universalis

13 Delamere FM, et al: Interventions for alopecia areata. Cochrane Database Syst Rev 2008:CD004413.

14 Suarez-Farinas M, et al: Alopecia areata profiling shows TH1, TH2, and IL-23 cytokine activation without parallel TH17/TH22 skewing. J Allergy Clin Immunol 2015;136:1277-1287.

15 Verros C, Rallis E, Crowe M: Letter: Alopecia areata during ustekinumab administration: co-existence or an adverse reaction? Dermatol Online J 2012;18:14.

$\$ 16$ Tauber M, et al: Alopecia areata developing during ustekinumab therapy: report of two cases. Eur J Dermatol 2013;23:912-913.

17 Slowinska M, et al: Alopecia areata developing paralell to improvement of psoriasis during ustekinumab therapy. J Dermatol Case Rep 2010;4:15-17.

18 Andrisani G, et al: Development of psoriasis scalp with alopecia during treatment of Crohn's disease with infliximab and rapid response to both diseases to ustekinumab. Eur Rev Med Pharmacol Sci 2013;17:28312836.

19 Tillack C, et al: Anti-TNF antibody-induced psoriasiform skin lesions in patients with inflammatory bowel disease are characterised by interferon-gamma-expressing Th1 cells and IL-17A/IL-22-expressing Th17 cells and respond to anti-IL-12/IL-23 antibody treatment. Gut 2014;63:567-577.

20 Xing L, et al: Alopecia areata is driven by cytotoxic T lymphocytes and is reversed by JAK inhibition. Nat Med 2014;20:1043-1049.

-21 Craiglow BG, King BA: Killing two birds with one stone: oral tofacitinib reverses alopecia universalis in a patient with plaque psoriasis. J Invest Dermatol 2014;134:2988-2990.

-22 Pan F, et al: Eos mediates Foxp3-dependent gene silencing in CD4+ regulatory T cells. Science 2009;325:1142-1146.

23 McDonagh AJ, Messenger AG: The pathogenesis of alopecia areata. Dermatol Clin 1996;14:661-670.

-24 Tobin DJ, et al: Antibodies to hair follicles in alopecia areata. J Invest Dermatol 1994;102:721-724.

Table 1. Loci with genome-wide association signals in AA

\begin{tabular}{ll}
\hline Chromosome & Immune genes associated with genome-wide signals \\
\hline 2q33.2 & $\begin{array}{l}\text { CTLA4 gene encodes for CD152, an immune checkpoint that downregulates T cell re- } \\
\text { sponses }\end{array}$ \\
\hline 4q27 & IL2/IL21 locus both promote CD8+ T cell function \\
\hline 6p21.32 & $\begin{array}{l}\text { HLA super locus which encodes for the histocompatibility leukocyte antigens. Especially, } \\
\text { HLA class II loci have shown a strong association with AA }\end{array}$ \\
\hline 6q25.1 & $\begin{array}{l}\text { Cytomegalovirus UL16-binding protein gene cluster (ULBP3) encodes for NKG2D ligand } \\
\text { Cells, but also on human CD8+ cytotoxic T cells and in some cases on CD4+ T cells }\end{array}$ \\
\hline 9q31.1 & $\begin{array}{l}\text { STX17 (Syntaxin-17) is a member of the soluble N-ethylmaleimide-sensitive factor- } \\
\text { attachment protein receptors (SNARE) superfamily, which is known for vesicular traf- } \\
\text { ficking and membrane fusion }\end{array}$ \\
\hline 10p15.1 & $\begin{array}{l}\text { IL2RA, also referred to as CD25, is associated with several autoimmune diseases and acts } \\
\text { as a regulatory T cell marker }\end{array}$ \\
\hline 11q13 & $\begin{array}{l}\text { PRDX5 (Mitochondrial peroxiredoxin-5) is an oxidative stress-associated protein ex- } \\
\text { pressed in hair follicles and induces the elimination of DNA-damaging reactive oxygen } \\
\text { species }\end{array}$ \\
\hline $\begin{array}{l}\text { Eos locus encodes for zinc finger proteins that can silence CD4+ regulatory T cells } \\
\text { through mediation of the Foxp3-dependent gene [2, 20, 22] }\end{array}$ \\
\hline
\end{tabular}




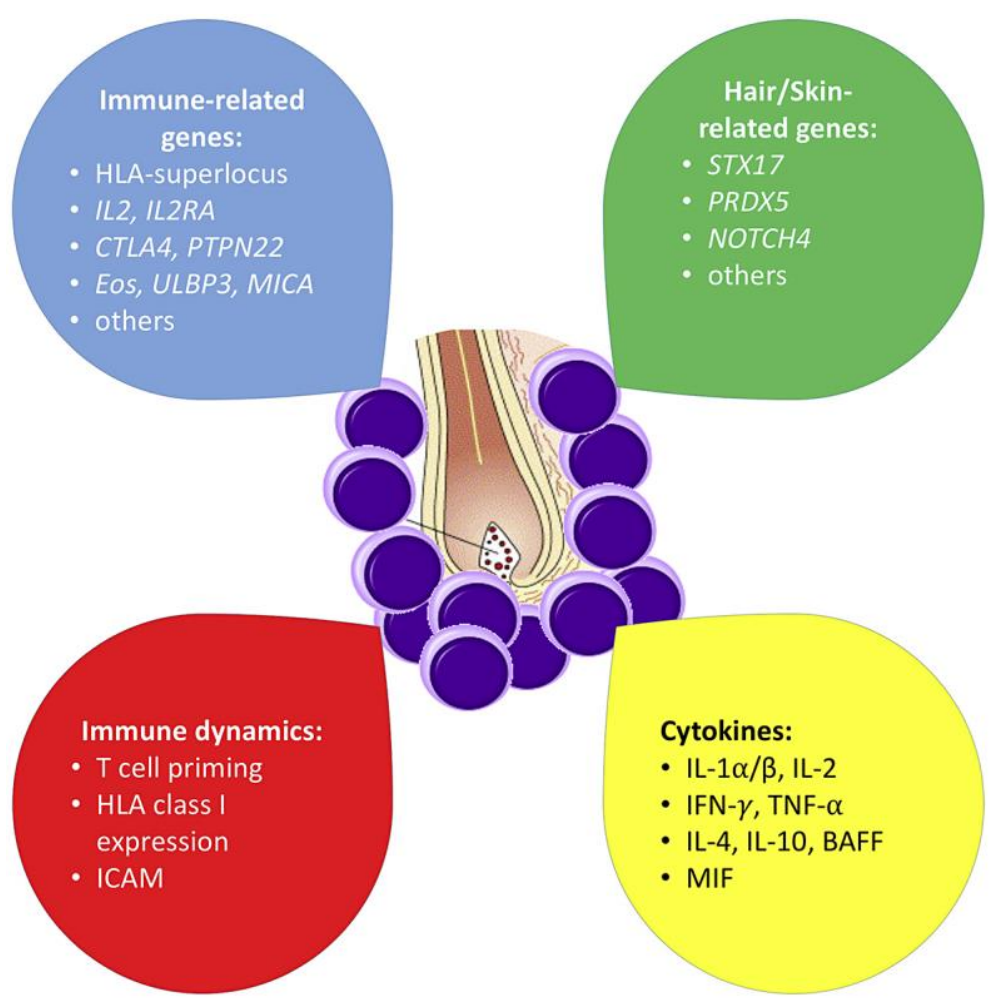

Fig. 1. Genes and immunologic factors contributing to the pathogenesis of AA.
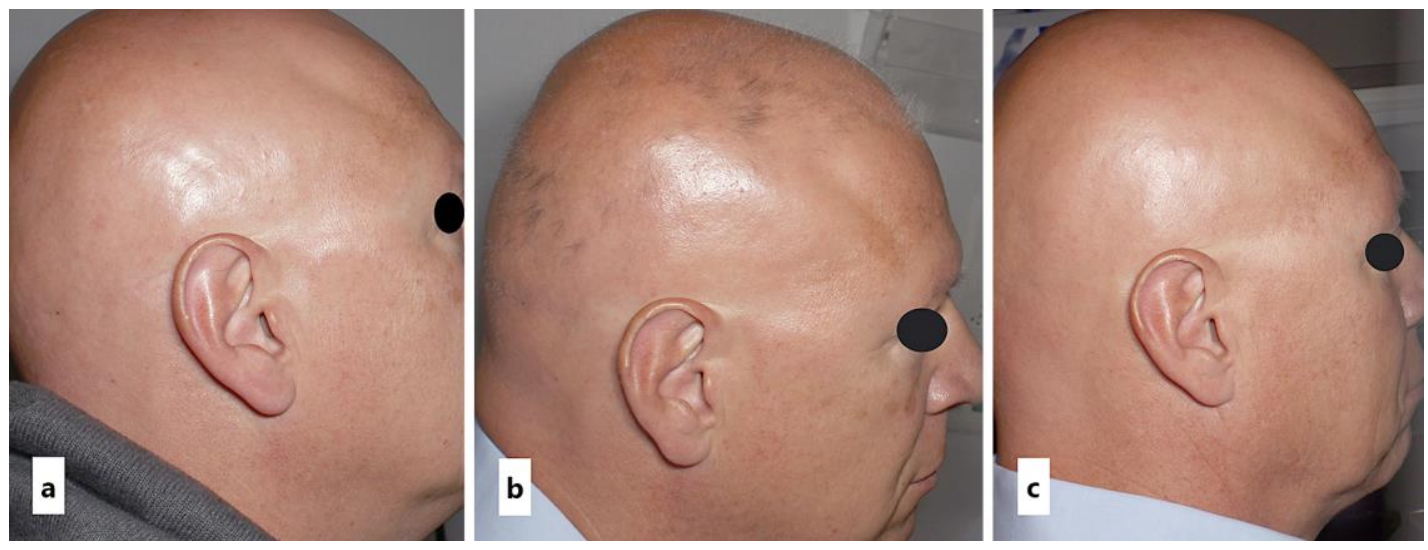

Fig. 2. a Unchanged state of alopecia areata universalis even after 2 months of therapy. b shows the regrowth of short terminal pigmented hair after 3 months, while c depicts the unfortunate relapse after 6 months of tofacitinib therapy. 